\title{
Effect of Institutional Related Criteria in Partner Selection: Case of Logistic Service Provider in Indonesia
}

\author{
Hally Hanafiah ${ }^{1 *}$, Anton Wachidin Widjaja ${ }^{1}$ \\ ${ }^{1}$ Faculty of Economics and Business, Universitas Indonesia \\ Email: hally.hanafiah@gmail.com
}

\begin{abstract}
The instability of collaboration has long been studied through an understanding of partner selection criteria (Jamali, 2004), but the applied criteria are not yet fully appropriate in determining collaboration partners. Factors related to partner resources and factors that explain relationship stability are two criteria between two firms that are often used in partner selection. While the change of external environmental factors in the form of institutional context which is a critical factor in improving the quality of partner selection (Williams et al., 2009) has not been fully utilized. Specific strategic contexts make the selection of partners highly variable Hitt et al. (2000) and Robson, (2002a) in addition to the uncertainties of the external environment outside the company, making institutional context a critical success factor for collaboration. A partner selection framework was proposed by combining the three partner selection criteria that feed into the supply chain integration process that results in logistical capabilities and company performance. The conceptual model was utilized in studying supply chain integration among logistics service providers in Indonesia.
\end{abstract}

Keywords: Partner Selection, Supply Chain Integration, Dynamic Capability

\section{Introduction}

Increased market demand as well as competition is inevitable due to complex and turbulent environmental changes (Valentina, Putra, Saherlan, 2016). According to White (2000); Geykens, Steenkamp et al. (2006) companies can create competitive advantage to grow either internally or externally. Limitations of resources and capabilities are the company's consideration of the choice of externally growing strategies (Das and Tang, 2008) through collaboration (Hoffmann and Schaper-Rinkel, 2001: 132). Collaboration is a process designed to enhance the capacity of services and create competitive advantage, through complementary partnerships of services, sharing information and forming collective responsibilities (Ellinher et al., 2000). Although collaboration is able to create competitive advantage through enhanced capability and quality of service (Isoraite, 2009), the risk of failure is also large enough to decrease service effectiveness (Holmberg and Cummings, 2009). 
According to Hitt et al. (2000) and Robson (2002a) the selection criteria are highly variable and strongly influenced by differences and changes in external environmental factors, so that the institutional context is considered a critical factor in the selection of collaborative partners of Williams et al. (2009). This research will explore the above paradox by looking for factors that support the success of the alliance and minimize the failure (Culpan, 2009) one of them through the selection of partners by determining more fixed criteria in accordance with the context of the external environment and industry. In this study, the third-party logistics industry was chosen as one of the main drivers of logistics performance in Indonesia's logistics system, an industry influenced by the institutional context through government involvement in the form of law, regulation and bureaucracy.

Indonesia logistic performance is in a low position among ASEAN countries due to the high cost of logistics. This large logistic cost contributed by logistic service provider. In addition, the high price disparity due to the industry region centered on one island is also influenced by the quality service of LSP such as responsiveness, reliability, tangibility, assurance and empathy. Therefore, supply chain integration between domestic logistic service provider companies is considered to increased level of service and reduce logistic cost. Increased productivity will affect logistic costs charged to the owner of the goods so that the situation would affect the competitiveness of domestic products in Indonesia.

The values of the institutional context can strengthen or weaken the collaboration of Bianchi (2003). The threat or business opportunity of regulators or governments, industry norms and communities in motivating and encouraging some companies to engage in collaboration is understood by using institutional theory (Hoffmann, 2000). Thus, rapid changes in the external environment and high uncertainties affecting the shift or development of strategies ultimately make the institutional context a dominant factor and desperately need to be considered in partner selection (Mahnke, 2001; Wei-Long Lee, 2014). Although the institutional context factors through institutional theory perspectives also contribute to the selection criteria selection process (Barriner \& Harrison, 2000; Casson \& Mol, 2006), a study examining the influence of the institutional context in the selection of collaborative partners is still very limited.

So, the purpose of this study was to examine how the impacts of the selection of partners that combine three groups of partner selection criteria simultaneously to the formation of effective supply chain integration through the creation of logistic capability among logistic service provider companies. Therefore, it needs frameworks and theories which are integrated for connecting motive integration that determines the type of partner selection criteria, the influence of the type of criteria for the selection of integration partners and the impact to the capabilities and performance of the company and partners. The empirical study was conducted on the logistic service provider companies in Indonesia which will conduct supply chain integration. The objective of this research was to determine the influence of selection partner and institutional criteria in the choice of supply chain integration partners towards the establishment of capability in creating a competitive advantage.

\section{Literature Review}

Strategic management and supply chain management both a dynamic process that encourages companies to create a competitive advantage through improved quality supply chain to adapt 
to environmental changes. Strategic management is more focused on developing competitive positions to create corporate excellence in generating performance (Porter, 1980, 1996). One of the strategies that have been selected through a supply chain integration to obtain resources and capabilities that are not wholly owned by each company (Dussauge \& Garrette, 1995). While supply chain management is to focus on how the competitive position can be created through the supply chain process more effective and efficient (Fisher, 1997). This study employed the theory of strategic alliance and used it in strategic management to formation of supply chain integration in the supply chain management.

\subsection{Partner Selection}

The success of collaboration depends on the determinants of each stage of collaborative evolution (Gulati, 1998) that consist of a forming phase in which the company decides on the right partner, the design phase in which the company and its partners set up governance in organizing collaboration and post-forming phases, whereby the company controls collaboration with and has giving results (Schreiner, Kale and Corsten, 2009). Thus, the company should consider the issue of partner selection by using a more comprehensive view that is focused on the selection of a selection criteria that is tailored to the context (Lin et al., 2008). The importance of successful integration partner selection becomes important in a dynamic and complex marketplace. Because the right partner can boost adaptability and reduce uncertainty in operations. In addition, partner selection involves a process of adjusting knowledge related to resources and capabilities among firms.

\subsection{Partner Selection Criteria}

The evaluation process of a set of criteria reflects the attributes that the company needs to obtain the right partner candidate. Selection criteria for partners have been widely used (see Kim and Lee, 2003; Das and He, 2006. However, in this study, the selection criteria was divided into two major criteria: the notion of task related motivation (Geringer, 1988 and 1991) and partnerrelated consideration (Glaister, 1996). Both sets of criteria are now widely used simultaneously in determining partners (Wei Long Lee, 2014).

\subsubsection{Task Related Criteria}

Task-related is associated with a specific task that is established and must be done in a collaboration. Gaining complementary resources and capabilities is the hope that every company collaborates. Consequently, the complementary capabilities make collaboration work better and achieve the goals of each company involved in collaboration (Inkpen and Ross, 2001). The most common and often identifiable form of collaboration is the resource-sharing alliance that focuses on the acquisition of complementary resources. Conceptually, the theory of resource based view underlies task-related criteria that emphasize the resources and capabilities of the focal firm to be able to compete effectively. The greater the complementarity among partners (complementarity), the more likely the success of a collaboration (Kale and Singh, 2009). 


\subsubsection{Partner Related Criteria}

Das and Teng (2006) summarizes partner-related criteria as organizational or interdependent suitability, complementary objectives, compatible culture or cooperation, previous relationships, mutual trust between top managers, equal status, reciprocal relationships and ease of communication. This set of criteria is focused on how companies can have better cooperation when allied with a focus on achieving organizational fit (Luo, 1998). These criteria emphasize on compatibility and trust between partners and mostly related to transaction costs (transaction cost economy theory). Partner compatibility refers to organizational compatibility between the culture and work style of the collaborating partner. The degree of conformity between partner firms has been found to be an important predictor of success or failure of collaboration (Shamdani and Seth, 1995). This set of criteria focuses more on how firms can have better cooperation when collaborating with a focus on organizational fitness or organizational fit (Shamdasani and Seth, 1995; Hagen 2002; Luo, 2002 and 1998). The goal of the compatibility partner is to ensure the continuity of relationship stability between partners which is an important criteria category in a collaboration (Anslinger, 2004).

\subsubsection{Legitimate Related Criteria}

This study adds an institutional context as a criterion of success factors of collaboration which incorporates legitimacy factors as one of the success factors of collaboration criteria to help focus on institutional pressure such as coercive, normative and cognitive more broadly and comprehensively (DiMaggio and Powell, 1983; Meyer and Rowan, 1977). Referring to the institutional context facing the company, the legitimacy because of institutional pressure from both the government, the association and the customer will be used separately as one of the criteria for selecting transport collaboration partners. Legitimacy is defined as a generalization of perceptions and assumptions to the needs, accuracy and suitability of corporate actions in systems socially constituted by norms, values and beliefs (Suchman, 1995: 574). Legitimacy also provides critical social resources that facilitate and complement financial and physical resources. Because collaboration has transactional and social traits, it is appropriate to test legitimacy in the context of collaboration. Collaborative activities involve activities of gaining and sharing risks and sharing both tangible and intangible resources (individual skills, knowledge, and contacts).

\subsection{Supply Chain Integration}

Increased complexity and associated risk sharing posed challenges in the supply chain (Chopra and Sodhi, 2004; Blackhurst et al., 2005; Tang, 2006). The company manages the complexity of the supply chain through an integrated supply chain (Schoenherr and Swink, 2012). The extent to which firms strategically link and align supply chains with their counterparts from upstream to downstream is a Supply Chain Integration (SCI) can be defined as (Jayaram et al., 2010; Schoenherr and Swink, 2012). In general, closer integration leads to improved performance (Forrester, 1961, Kim, 2009). Integrating supply chain processes with customers and suppliers allows companies to improve and simplify information and data exchange, which can lead to increased product and material flows throughout the supply chain (Wiengarten et al., 2013). In addition, SCI can enable companies to access various resources and capabilities in the form of knowledge embedded in other supply chain members and then enhance enterprise innovation (Craighead et al., 2009; Cao and Zhang, 2011). 
Integration can be defined both from an internal perspective if it refers to integration between different functional areas within company boundaries and external perspectives when referring to how firms are integrated with upstream and downstream supply chain partners such as customers and suppliers (Flynn et al., 2010). Supply chain integration introduces the capability of exploiting the rapidly changing market opportunities (Uzi, 1997). The integration between supply chain partners can be the source of new product ideas (Kalwani, Narayandas, 1995). In addition, Supply chain integration makes chain members have high capability (responsiveness) in reacting to changes in the external environment. Closed integration enables supply chain partners to increase competence to meet customer needs with flexible offerings (Simatupang and Sridharan, 2005). Companies working with partners will benefit from the integration of the supply chain (Barratt and Oliveira, 2001; Callioni and Billington, 2001).

Flynn et al. (2010) found that the relationship of supply chain collaboration and company performance is complex and has various constructs. To understand the relationship of supply chain collaboration and performance, it is necessary to test how each dimension of supply chain collaboration is related to different performance dimensions. Given that the inconsistent findings of value from supply chain collaboration stemming from differences in the definition and operation of key constructs (Autry et al., 2014), a deep understanding of the definitions of each dimension of supply chain collaboration is required.

\subsection{Supply Chain Performance}

Extensive research has been done in assessing the impact of supply chain integration on company performance (Schoenherr and Swink, 2012). Strategies leading to the integration of customers and suppliers have a higher impact on the level of firm performance into or functional integration into Frohlich and Westbrook (2001). Having a close and integrated supply chain relationship is a means to achieve superior performance in terms of cost, quality, flexibility, and delivery (Flynn et al., 2010; Narasimhan et al., 2010) In addition Flynn et al. (2010) identifies that internal integration of the firm is closely linked to business and operational performance. While integration with customers only closely related to operational performance. Schoenherr and Swink (2012) identified that internal integration reinforces the impact of supplier and customer integration on delivery performance and flexibility but not on quality and cost performance. Elmuti et al. (2008) show that positive and substantial improvements in overall performance is due to the integration and coordination of the internal functions within the firm and effectively linking them with their external suppliers. Although the selection of partners in the supply chain is a strategic decision of supply chain integration, a measure of performance in the study not only financial performance (revenue, profitability) but also non-financial performance (customer, supplier satisfaction).

\subsection{Relationship of Partner Selection and Supply Chain Integration}

Motivation is an important determinant of activities related to supply chain integration within a company (Chen, Lee, \& Wu, 2008). Thus, in complex external environments, the prominent collaboration motivation is to combine complementary resources (Hagedoorn, 1993), so that the most valuable organizational competencies can be developed especially those that can create competitive advantage (Das and Teng 2000). Each company hopes to achieve significant alignment or conformity between the task-related criteria to ensure successful integration to enable full integration and company targets respectively (Inkpen and Ross, 2001). 
Sharing resource alliances is a foundation of integration that focuses on complementary resources. Complementarity is an important element in the selection of partners and the determination of attractiveness as it influences the description of the orientation, ability, and activities of the partnering organization can be successfully integrated (Spekman and Sawhney, 1990). Coordination between partners will be easier if partners have complementary skills and resources (Harrison et al., 2001). It can be inferred that the capabilities and resources that copy completes are needed in all collaborative contexts as well as the minimum requirements for integration. The right integration partner is one company that can contribute resources and capabilities that the focal firm lacks and ultimately determines the continuity of the collaboration.

Hypothesis 1: Task Critical Factor to positively influence the effectiveness and efficiency of Supply Chain Integration.

The current socio-political and economic context affects companies (Walter et al., 2008), where the influence of these complex environmental conditions raises three institutional pressures (Hoffman 2000): government regulatory pressure, industry norms and normative pressure. Because this is in line with DiMaggio \& Powell's view, 1983; Dacin, Hitt and Levitas, 1997; Geringer, 1988; Hitt et al., 2000, then another set of criteria relating to the institutional and pressing aspects in which such collaboration is formed and running needs to be of concern to companies that will collaborate. This pressure can increase the legitimacy of partner companies, and in turn can increase their chances of survival (Dacin et al., 2007). Companies that have legitimacy needs will be encouraged to identify partners who can meet those needs particularly if they are an important legitimacy for focal enterprises (Dacin, Oliver and Roy, 2007). The determination of partners who can meet the needs of market legitimation, relational, social, investment, or alliance become criteria of partner selection is also important. Based on these argument, the researchers conclude that institutional must be one of critical factor that influence the selection partner of integration.

Hypothesis 2: Institutional Critical Factor to positively influence the effectiveness and efficiency of Supply Chain Integration.

Any strategy will not work if this relationship is not applicable if it does not speed up compatibility in the first and foremost ranking of success factors of integration or collaboration (Hagen, 2002). It was found that the degree of compatibility became an important predictor of the success or failure of collaborative ventures between partners of companies (Shamdasani \& Seth, 1995). In addition, the relational stability or relationship formed between partners during collaboration is one of the key determinants of successful collaboration (consistency, readiness and effectiveness). The quality of the relationships formed with these partners will shape better supply chain performance (Hsu, 2005).

Hypothesis 3: Partner Critical Factor to positively influence the effectiveness and efficiency of Supply Chain Integration.

Short time planning time, minimum inventory demands, low transport mode utilization and overall operational performance are issues that are closely related to supply chain integration (Browning and White 2000). Through Supply Chain Integration, the company will be able to reduce transaction costs and risks, increase profits through improved asset productivity 


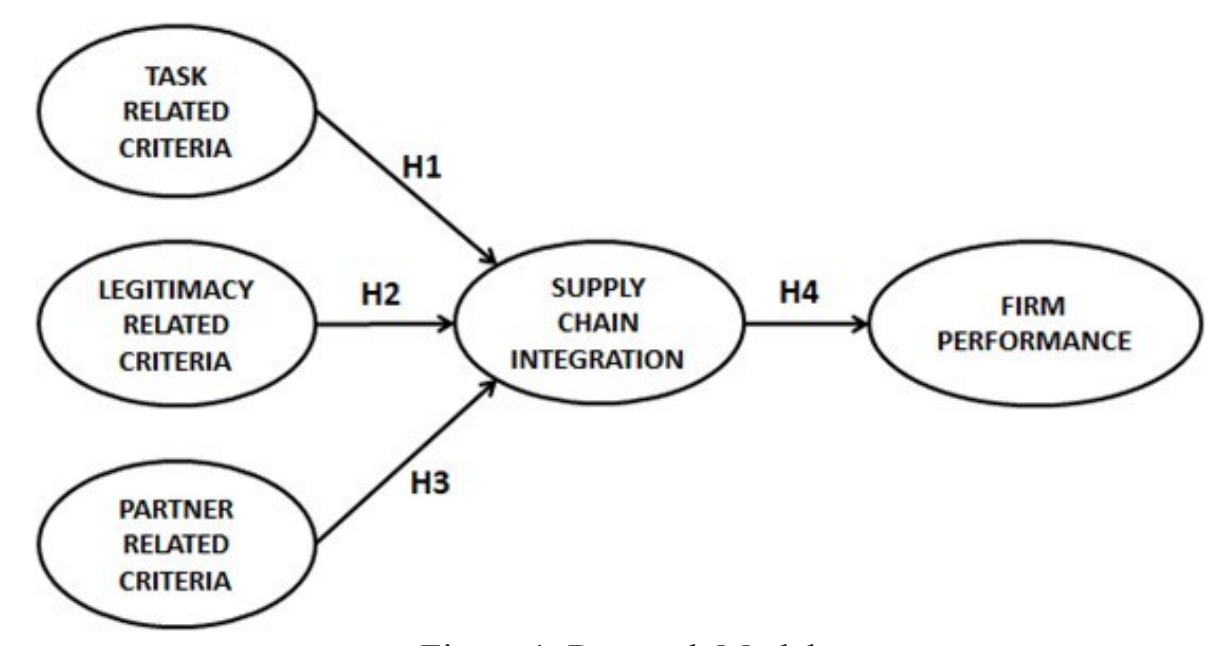

Figure 1. Research Model

and reduced inefficiency. Supply chain integration offers an opportunity for Logistic Service Providers to develop business plans. Previous research has found that having a close and integrated supply chain relationship is a means of achieving superior performance (Flynn et al., 2010; Narasimhan et al., 2010). Devaraj et al. (2007) identified that integration with suppliers significantly contributes to the performance of operational firms in terms of cost performance, quality, flexibility, and delivery and does not occur if integration with customers. Internal enterprise integration is related to business and operational performance but not to integration with suppliers (Flynn et al., 2010). Instead, integration with customers is only related to operational performance. The arguments lead to the following hypothesis.

Hypothesis 4: Supply chain integration to positively influence the performance of the firm.

\section{Research Methodology}

The object of this research is companies that collaborate in the logistics service provider industry that provides logistic services to producers and end users. Companies that have been and are collaborating at least three years' operating in the geographical region of Indonesia and has a distribution network in several big cities. Therefore, this research employed quantitative method which is equipped with qualitative method. The definition of qualitative methods here is more emphasized on literature studies and interviews (open questions and discussions) with business service logistics services aimed at generating questionnaires as well as analysis and writing of research results. Furthermore, this research will be more focused on quantitative methods through SEM (Structural Equation Model) to test the validity and reliability of each indicator that form the latent variable as well as test the level of relationship among the latent variables in the research model. Finally, qualitative methods will be conducted again through second stage interviews with the aim of discussing the results of the previous quantitative analysis. 


\section{References}

M Ahuja G. 2000. The duality of collaboration: inducements and opportunities in the formation of interfirm linkages. Strategic Management Journal, March Special Issue 21: $317-343$.

Africa Arino \& Peter Smith 2010. The Role of Fairness in Alliance Formation. Strategic Management Journal. 31: 1054-1083 (2010).

Barney, Jay (1991).” Firm Resources and Sustained Competitive Advantage”. Journal of Management; 17, 1.

Barney J. 2001. Is the resource-based 'view' a useful perspective for strategic management research? Yes. Academy of Management Review 26(1): 41 - 56.

Barney J. 2002. Gaining and Sustaining Competitive Advantage. Prentice Hall: Upper Saddle River, NJ.

Cao, M. and Zhang, Q. "Supply Chain Collaboration: Roles of Interorganizational Systems, Trust, and Collaborative Culture”. Springer Publisher, DOI 10.1007/978-1-44714591-2, 2013.

Chakravarthy, Bala (1997). "A New Strategy Framework for Coping with Turbulence”. Sloan Management Review; 38, 2

Chen H. M., Chen T. J. (2003). Governance structures in strategic alliance: Transaction cost versus resource based perspective. Journal of World Business, 38

Das, T. K., and B. Teng (1998). "Resource and Risk Management in The Strategic Alliances Making Process,” Journal of Management, Vol. 24, No. 1, 1998, pp. 21-42.26, 31-61.

DiMaggio, P. D., \& Powell, W. W. (1983). The iron cage revisited: Institutional isomorphism and collective rationality in organizational fields. American Sociological Review, 48, $147-160$.

Flynn, B.B. and Flynn, E.J. (2005), "Synergies between supply chain management and quality management: emerging implications", International Journal of Production Research, Vol. 16 No. 15, pp. 3421-63.

Gulati, R., (1995). Social structure and alliance formation patterns: a longitudinal analysis. Administrative Science Quarterly 40 (4), 619-652.

Haiying Lin, Nicole Darnall 2014. Strategic Alliance Formation and Structural Configuration. Journal Business Ethics.

Hoffman A. (2000). Social drivers. Chap. 6: competitive environmental strategy: A guide to changing the business landscape (pp. 105-126). Washington, DC: Island Press. 
Holmberg, S.R; Cummings, J.L. (2009), "Building successful strategic alliances strategic process and analytical tool for selecting partner industries and firms", Long Range Planning, Vol. 42 No. 2, pp. 164-93.

Hoskisson, R.E.; Lorraine Eden; Chung Ming Lau; \& Mike Wright (2000). "Strategy in Emerging Economies”. Academy of Management Journal, 43, 3.

Hitt, M.A. (2011). Relevance of Strategic Management Theory and Research for Supply Chain Management. Journal of Supply Chain Management; 47, 1;

Jeffrey L.Cummings and Stevan R. Holmberg, 2012. Best Fit Alliance Partner: The Use of Critical Success Factors in a Comprehensive Partner Selection Process. Long Range Planning 43. 136-159

Kale P. and H. Singh (2009), Managing Strategic Alliances: What do we know now and where do we go from here? Academy of Management Perspective August 2009, 45-62

Kanter, RM. (1994), Collaborative advantage: the art of alliance, Harvard Business Review, Vol. 72 No. 4, pp. $96-10$

Kwon, I.W. and Suh, T. (2005), "Trust, Commitment and Relationship in Supply Chain Management: A Path Analysis. Supply Chain Management: An International Journal Vol. 10, 1, 2005, pp. 26-33. Lambert, DM and Cooper, MC. 2000: Issues in supply chain management. Industrial Marketing Management 29 : 65-83

Liane Okdinawati, Togar M. Simatupang, Yos Sunitiyoso (2015), Modelling Collaborative Transportation: Current State and Opportunities for Future Research. Journal of Operation and Supply Chain Management Volume 8 Number 2 p. 96-119

Mahendrawathy, E.R., Wasusr, W., Astuti, H.m. dan Herdiyanti, A., "The Service Quality of Indonesia's Logistic Provder in Preparation for ASEAN Economic Community”, Industrial Engineering, Management Science and Application, 2015.

Michael A. Hitt, Edward Levitas, Jean-Luc Arregle, Anca Borza, Partner Selection in Emerging And Developed Market Context 2000. Academy Management of Journal, 43, 3.

Michael A. Hitt, David Ahlstrom, M. Tina Dacin, Edward Levitas, Lilia Svobodina 2004. The Instituational Effects on Strategic Alliance Partner Selection in Transition Economies: China vs. Rusia. Organization Science Vol. 15 No. 2. Pp. 173-185.

Nelson RR, Winter S. 1982. An Evolutionary Theory of Economic Change. Harvard University Press: Cambridge, MA. Ng DW. 2007. A modern resource-based approach to unrelated diversification. Journal of Management Studies 44(8): 1491 - 1502.

Park, S. H.; Ungson, G. R. (2001). Interfirm Rivalry and Managerial Complexity: A Conceptual Framework of Alliance Failure. Organization Science, 12 (1), 37-53 
R. Duane Ireland, Michael A. Hitt, Deppa Vaidyanath (2002), Alliance Management as a Source of Competitive Advantage, Journal of Management

Sirmon DG, Hitt MA, Ireland RD. 2007. Managing firm resources in dynamic environments to create value: looking inside the black box. Academy of Management Review 32(1): $273-292$.

Teece, D. J.; G. Pisano; \& A. Shuen (1997). "Dynamic Capabilities and Strategic Management”. Strategic Management Journal 18 (7): 509-533.

Wernerfelt, B. (1984), A Resource-based View of the Firm, Strategic Management Journal, $5,171-180$.

Zeynep Emden, Roger J. Calantone, Cornelia Droge 2006. Collaborating for New Product Development: The Selecting Partner with Maximum Potential to create Value. Journal of Production Innovation Management 23; 330-341.

Zollo M, Reuer JJ, Singh H. 2002. Interorganizational routines and performance in strategic alliances. Organization Science 13(6): 701 - 713.

Zollo M, Singh H. 2004. Deliberate learning in corporate acquisitions: post-acquisition strategies and integration capability in U.S. bank mergers. Strategic Manage- ment Journal 25(13): 1233 - 256. 